\title{
Excess Sludge Reduction in Waste Water Treatment Plants
}

\author{
Mahmudul Kabir, Masafumi Suzuki and Noboru Yoshimura \\ Akita University \\ Japan
}

\section{Introduction}

Household waste water is taken under WWT (W Waste $\underline{\text { Water }}$ Treatment) process and treated water is removed to the nature. Biological analysis method using activated sludge is well known and used method for the treatment of waste water as the running cost is cheap. But, a large amount of excess sludge is produced in the Waste Water Treatment $\underline{\text { Plants }}$ (WWTPs) which is a great burden in both economical and environmental aspects. Fig.1 is an example of annual industrial waste of Japan (Ministry of the Environment, Government of Japan, 2010). Sludge related garbage occupied $44.2 \%$ of the total industrial waste. In which about $86,860,000$ ton of sludge related to WWTPs was produced in 2007. The excess sludge contains a lot of moisture and which is not easy to treat. There are several works done by many scientists to treat the excess sludge (Ide, 1990; Eckenfelder \& Grau, 1998; Miyoshi, 2006; Sawada et al., 2005; Wei et al., 2003). These byproducts of WWTPs are dewatered, dried and finally burnt into ashes. Some are used in farm lands as compost fertilizer. The less dump places for ashes and the high cost to treat the excess sludge are huge burdens to our society. In Japan, an average of Yen $20,000 / t$ is needed to treat of excess sludge. Again, burning of excess sludge evacuates the $\mathrm{CO}_{2}$ in air, which is a cause of global warming. So, the reduction of excess sludge is a growing demand to the modern society. It is not only a headache of Japan, but also to the rest of the world.

\section{Excess sludge reduction}

There are some reports informing the success in order to reduce the excess sludge by adding fallen leaves in the aeration tank where activated sludge is kept (Yoshida, 2000). But, the mechanism is no yet clearly understood. Some efforts were carried out to increase the self decay of activated sludge prolonging the aeration period (Yoshida, 2000). However, these attempts are dependant on biological properties of activated sludge and difficult to achieve good results at every time. Again, prolonging of the aeration period brings the excess economical burdens. However, recently, a new approach has been started to minimize the excess sludge of WWTPs. A part of activated sludge is treated under cell lysis. The treated sludge or a part of the treated sludge can be decomposed by non-treated sludge when they are sent to the aeration tank and thus the excess sludge can be minimized. Several reports regarding to cell lysis in order to reduce excess sludge were published including ozonation, milling process with beads, revolving disks methods etc. (Ide, 1990; Eckenfelder \& Grau, 1998; 
Miyoshi, 2006; Wei et al., 2003; Yoshida, 2000; Sano et al., 2005; Yasui \& Shibata, 1994). But, however, the methods are still on the process and a new and effective technology is still a demand in this branch. We have developed a new process to minimize the production of excess sludge with the ferrite particles (Kabir et al., 2007). We will introduce some innovative methods for reduction of excess sludge by using ferrite particles and permanent magnets.

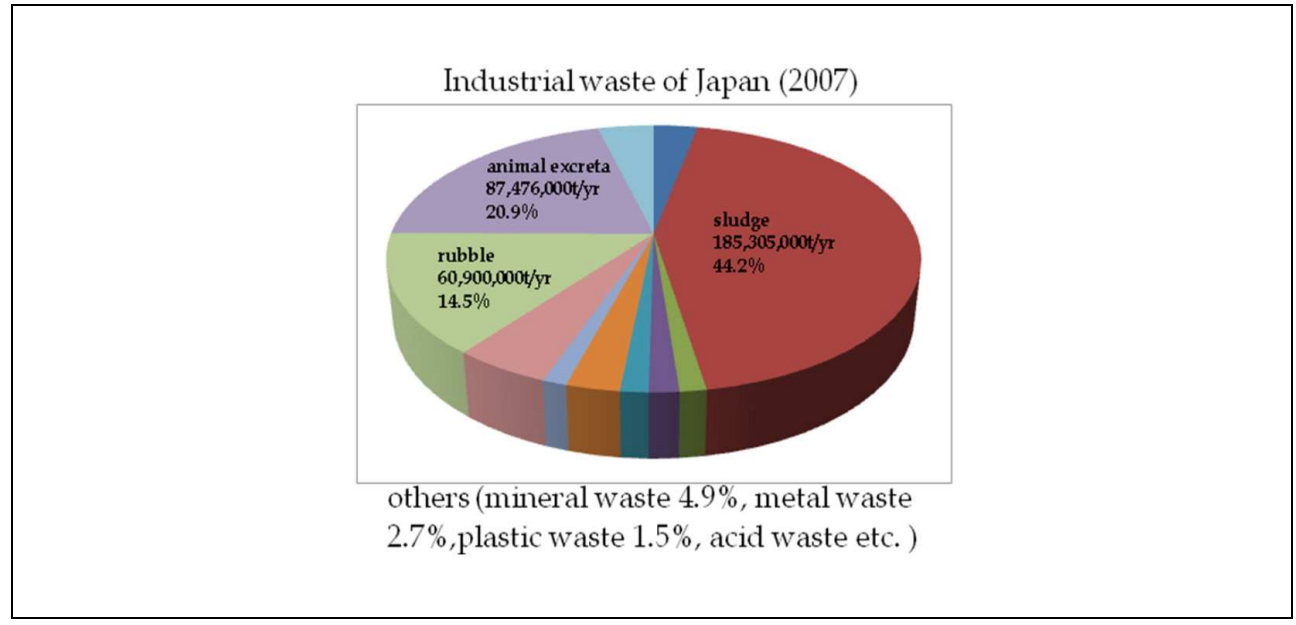

Fig. 1. Annual industrial waste in Japan

\subsection{Excess sludge production process}

Biological analysis method is the most widely used method for the household waste water treatment. This method uses biological groups of living organisms which possess good settling characteristics. In general, they are called activated sludge. The living organisms decompose the biological nutrients from the waste water and thus purify the waste water from biological waste. The diagram of the WWT using activated sludge can be seen in Fig.2 (Ide, 1990; Eckenfelder \& Grau, 1998; Miyoshi, 2006). It shows a WWTP model diagram. In order to separate big wastes from waste water, it is run under some primary processes and then waste water is finally put to the aeration tank where activated sludge is kept. Air is supplied to decompose the biological waste in the aeration tank. From the aeration tank, the treated water is supplied to the settling tank where water is separated from activated sludge by settling the sludge naturally. The treated water is taken out as effluent and the activated sludge is returned to the aeration tank. The excess activated sludge is discarded from settling tank when it is necessary. The amount of excess sludge $(\Delta X)$ can be expressed by the following equation (Ide, 1990; Eckenfelder \& Grau, 1998; Miyoshi, 2006);

$$
\Delta X=\mathrm{a} S_{\mathrm{r}}-\mathrm{b} X
$$

Here,

$\mathrm{a}=$ gross yield coefficient of sludge

$S_{\mathrm{r}}=$ BOD removal; $Q_{\mathrm{I}} \times C_{\mathrm{I}} \times\left(C_{\mathrm{I}}-C_{\mathrm{O}}\right) / C_{\mathrm{I}}[\mathrm{kg} / \mathrm{d}]$ 
$\mathrm{b}=$ Specific biomass decay due to self oxidization $[1 / \mathrm{d}]$

$X=$ amount of activated sludge $[\mathrm{kg}]$

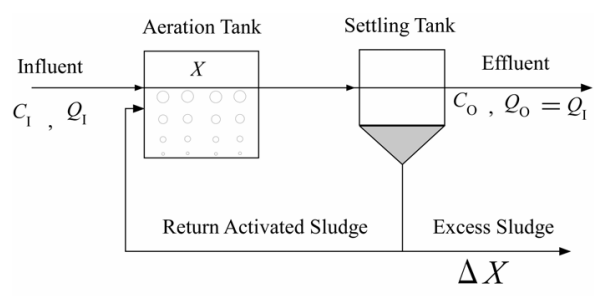

Here,

$$
\begin{aligned}
& C_{\mathrm{I}}: \text { BOD of waste water }\left[\mathrm{kg} / \mathrm{m}^{3}\right] \\
& Q_{\mathrm{I}}: \text { amount of influent }\left[\mathrm{m}^{3} / \mathrm{d}\right] \\
& Q_{\mathrm{O}}: \text { amount of effluent }\left[\mathrm{m}^{3} / \mathrm{d}\right] \\
& C_{\mathrm{O}}: \text { BOD of effluent }\left[\mathrm{kg} / \mathrm{m}^{3}\right] \\
& X: \text { amount of activated sludge }[\mathrm{kg}] \\
& \Delta X \text { :excess sludge }[\mathrm{kg} / \mathrm{d}]
\end{aligned}
$$

Fig. 2. Model diagram of a WWTP

It can be understood from the above equation that the zero emission is possible for a WWTP when $a S_{r}$ is less or equal to $b X$. The parameters ' $a$ ' and ' $S_{r}$ ' are totally dependant on the biological characteristics of activated sludge and it is not easy to handle them. Again, increasing of self decay by oxidization needs extra electric power causing economical and environmental burden. If we consider an amount of return sludge (i.e. $W$ ) with cell lysis treatment and send them to the aeration tank for decomposing by non-treated sludge, the excess sludge production can be minimized theoritically. For ' $h$ ' is to be the diverting rate of treated sludge to activated sludge then the amount of ' $W$ ' can be calculated from the following equation (Yoshida, 2000),

$$
W=\Delta X /(1-\mathrm{h})
$$

\subsection{Magneto-Ferrite treatment}

This is a treatment method of excess sludge in which the collisions of ferrite particles with activated sludge can trigger to the sterilization and cell lysis of activated sludge. The treated sludge is sent to the aeration tank and decomposed by activated sludge. The motion of ferrite particles are controlled by magnetic flux. Sterilization of microorganisms was reported with magneto-ferrite treatments by Yoshimura group (Ito et al., 1992; Murayama et al., 1993; Yoshimura \& Suzuki, 1991; Yoshimura et al. 1994). We used this treatment process to disrupt the cell wall of microbes of activated sludge. Ferrite particles are magnetic materials and can easily be separated from the activated sludge by a magnet. They are non toxic and in soluble in water. This idea is quite similar to the milling process but it is better than to use ceramic beads, as ferrite particles can be as small as $\sim \mu \mathrm{m}$ order. 
So, instead of beads, the collisions produced by the ferrite particles can hopefully break down the microbes of the activated sludge.

Ferrite particles are kept with activated sludge in a test tube and the test tube is exposed in the magnetic flux. The ferrite particles are gathered together in the magnetic flux and they are scattered when they are out of the magnetic flux. The ferrite particles of diameter $\mathrm{D}$, make a gap with a diameter of $\mathrm{D} \sqrt{ }(3 / 2)-\mathrm{D}$, as shown in Fig.3 (Murayama et al., 1993; Yoshimura et al. 1994). This gap changes its position with time as the ferrite particles are scattered and collected together in the test tube periodically. While the ferrite particles change their positions inside the test tube, activated sludge is captured in the gap produced by the ferrite particles. Thus, collisions occur in between the ferrite particles and the floc of activated sludge. The collisions can possibly crush the cell wall of microbes of the activated sludge which leads to sterilization of the microbes. Collisions occurred with ferrite particles and sludge which may lead to the cell lysis. The two miniature WWTPs were run for a fixed period of time with Conventional Activated Sludge (CAS) and Extended Aeration (EA) process (Kabir et al., 2007, 2009). Magneto-ferrite effect was applied for about 4 weeks in the case of CAS and found about $42 \%$ of excess sludge reduction with magneto-ferrite treatment of sludge comparing to the nontreated sludge. For EA process, we achieved the zero emission at lab. scale using this magneto ferrite treatment. For larger amount of sludge reduction, a rotary treatment plant was propsed and tested by miniature WWTPs and found $72 \%$ of sludge reduction (Kabir et al., 2010). Again, electromagnets were used to control the movements of ferrite particles (Kabir et al., 2012). Electro magnets can be controlled easily with an AC supply. Sterilization and cell lysis were found for activated sludge with the input voltage of $100 \mathrm{Vp}-\mathrm{p}$ of square wave. Thus, these methods will pave the way of excess sludge reduction in WWTPs.

\subsubsection{Test tube plant (Kabir et al., 2007, 2009)}

The test tube plant diagram model can be seen in Fig.4. Two permanent magnets were placed in on a plate. The plate was connected to a shaft of a motor by a joint. The circular rotation of the motor is changed into linear motion with the shaft of the joints. Two test tubes were fixed on the way of the magnetic flux. The capacity of the test tubes is $100 \mathrm{ml}$. Adequate ferrite particles were kept in the test tubes. The activated sludge from the settling tank was let to come to the test tube, treated and then sent back to the aeration tank. The amount of the activated sludge for treatment was controlled in a way so that the activated sludge can be kept in the magnetic flux for about $3 \mathrm{~h}$. Thus the activated sludge was happened to get the magneto-ferrite effect for $3 \mathrm{~h}$ and the microbes of the sludge get disrupted.

The sterilization of the microbes was investigated by counting the viable cells of microbes in the activated sludge using Easicult T.T.C. (Orion Diagnostica) model chart. Easicult is a test tube with a slide of agar to culture the microbes. After culturing the microbes of the activated sludge for $24-48 \mathrm{~h}$ at $28^{\circ} \mathrm{C}$ in a constant temperature and humidity chamber, the viable cell number in $1 \mathrm{ml}$ solution can be known by comparing with the model chart. After counting the viable cells of the treated activated sludge, the Viable Cell Coefficient (VCC) is calculated in the following way,

$$
V C C=\frac{\text { viable cell number of treated activated sludge }}{\text { viable cell number of initial stage of the activated sludge }} \times 100
$$




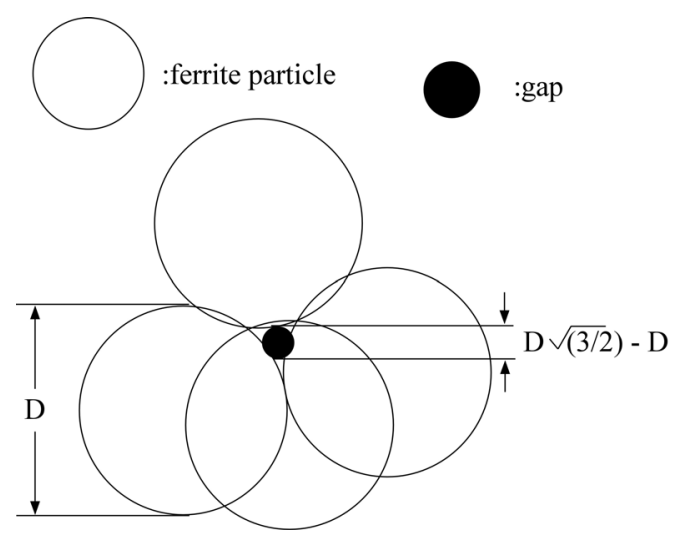

Fig. 3. Estimated gap made by ferrite particles

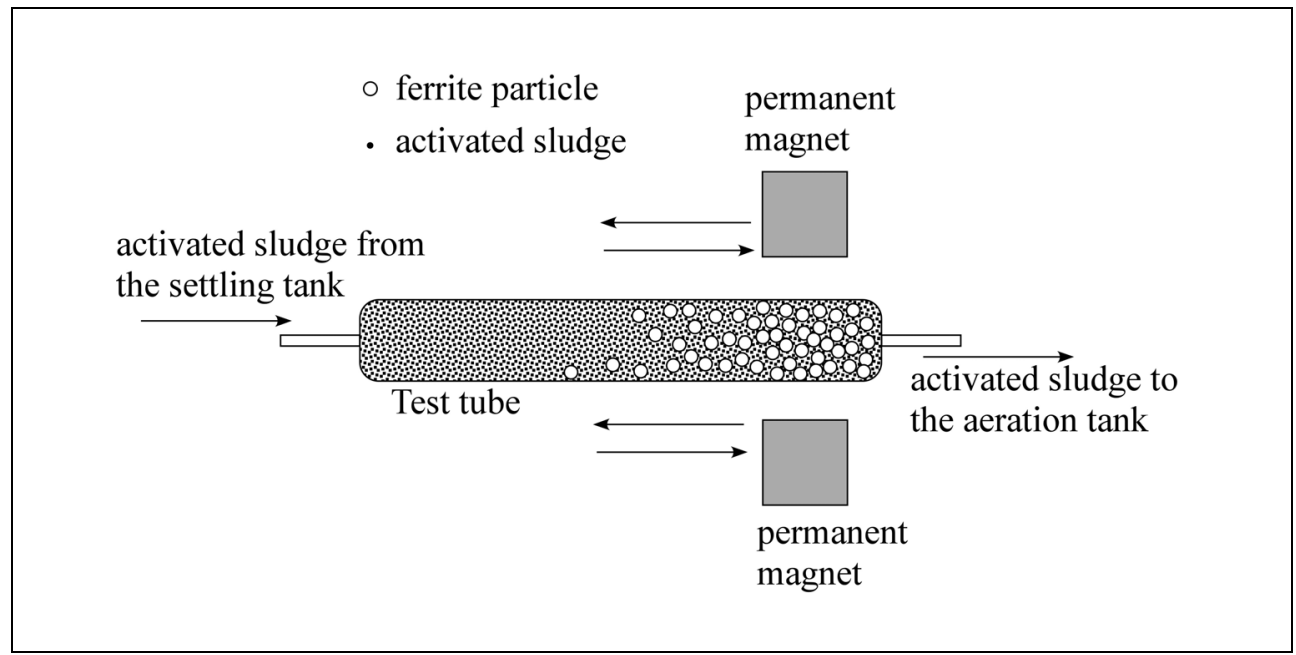

Fig. 4. Model diagram of test tube treatment plant

The decrease of VCC means the proceeding of sterilization and cell lysis. The process and the idea are very simple and effective. The excess sludge is taken in a glass made test tube with ferrite particles and which is kept still. The test tube is located in between the changing magnetic flux produced by a pair of moving magnets. These magnets move periodically as shown in Fig.4. The ferrite particles are collected together when they are exposed in the magnetic flux. Oppositely, they are scattered in the test tube when they are out of the magnetic flux. This movement continues periodically and thus results to the local frequent changes of water pressure and collisions occurred between the ferrite particles and the activated sludge. To determine the parameters of the magneto-ferrite system, several 
experiments were performed under several circumstances. These five types of experiments were performed to select the parameters,

a. The shape of the ferrite particles,

b. The size of the ferrite particles,

c. The amount of the ferrite particles,

d. The speed of the moving magnets and

e. The density of magnetic flux.

Each experiment was followed by the written processes,

1. Essential amount of activated sludge were taken to a beaker for the measurement of the initial amount of microbes.

2. In a glass test tube, $90 \mathrm{ml}$ of activated sludge was taken.

3. Necessary amount of a certain size of ferrite particles were added in the test tube.

4. Magneto-ferrite treatment was applied to the activated sludge of the test tube for 2, 4 and $6 \mathrm{~h}$.

5. Viable cell was counted for treated activated sludge after each experiment. The living cell number was compared with that of the initial stage of activated sludge to justify the degree of sterilization.

Thus several experiments were performed to determine these parameters. The experiments showed that for a $100 \mathrm{ml}$ of test tube, the better sterilization of the microbes can be achieved with the $30 \mathrm{~g}(333.3 \mathrm{~g} / \mathrm{L})$ of ferrite particles. The necessary shape of the ferrite is round and the grain size is less than $53 \mu \mathrm{m} .90 \mathrm{ml}$ of activated sludge can be treated at a time and the necessary magnetic flux and the speed of the magnets are $165 \mathrm{mT}$ and 1.5 1.8 cycles/s, respectively. These parameters were used to evaluate sludge reduction experiment for miniature WWTPs.

Two miniature WWTPs (Fig.5) were run with CAS and EA method. The biological parameters used in this experiment were shown in Table 1 (Miyoshi, 2006). We measured the Mixed Liquor Suspended Solid (MLSS) for aeration tanks of both WWTPs. We cast out the excess sludge when the value of MLSS had crossed the level described in Table 1 . The amount of the removed sludge was measured after the processes of dewatering and drying of sludge. Their values evaluated the effect of magneto-ferrite treatment. One thing is to be noted that the measurement of BOD takes about 5 days, so we preferred to measure Chemical Oxygen Demand (COD) instead of measuring BOD for relevant measurements. In this experiment, we used a COD meter (Quick COD; Central Kagaku Co.) to measure the COD of effluent. The COD removal efficiency was calculated for both treatment and nontreatment of magneto-ferrite effect. Here is the equation to calculate the value of COD removal efficiency (Miyoshi, 2006),

$$
\text { COD removal effficiency }=\frac{\text { CODinfluent }- \text { CODeffluent }}{\text { CODinfluent }} \times 100
$$

The methods to carry out the experiments will be described below;

1. Certain amount of artificial waste water was put in the reservoir.

2. The waste water was sent to the aeration tank by a pump (Cassette Tube Pump SMP-23, Tokyo Rikakikai Co.). The amount of the waste water is controlled by this pump according to the two methods described in Table 1. 
3. The activated sludge which had gathered in the settling tank was sent back to the aeration tank by a pump (Roller Pump; Furue Science Co.) for a fixed period of time. It is to be noted that magneto-ferrite effect is applied on system 2 whether another system was kept without any of the treatment.

4. In order to verify the effect of the magneto-ferrite treatment, the MLSS was measured periodically for the each of the aeration tanks. The excess sludge was removed if necessary, then dried and measured the amount of the sludge.

5. The COD of the effluent was measured periodically by a COD meter and COD removal efficiency was calculated.

The experiments were performed to make clear the effect of the magneto-ferrite treatment; so the major conditions were kept same for both WWTPs (system 1) and system 2. However, the values of MLSS of the two aeration tanks were little different at the initial stage which was not so big in amount and was acceptable. The ingredients of the artificial influent were as follows;

1. Peptone (Becton, Dickinson and Co.) $0.5 \mathrm{~g} / \mathrm{L}$

2. Glucose (Kanto Chemical Co.) $0.5 \mathrm{~g} / \mathrm{L}$

3. Yeast (Becton, Dickinson and Co.) $0.25 \mathrm{~g} / \mathrm{L}$

4. Ammonium Dihydrogenphosphate $\left(\mathrm{NH}_{4} \mathrm{H}_{2} \mathrm{PO}_{4}\right)$ (Kanto Chemical Co.) $7 \mathrm{mg} / \mathrm{L}$

5. $25 \%$ Ammonia water (Wako Pure Chemical Industries Ltd.) $1 \mathrm{~mL} / \mathrm{L}$

6. The $\mathrm{pH}$ values (6-8.5) were measured regularly of the activated sludge and controlled the value with $\mathrm{NaOH}$ (Nacalai Tesque) dropping if needed.

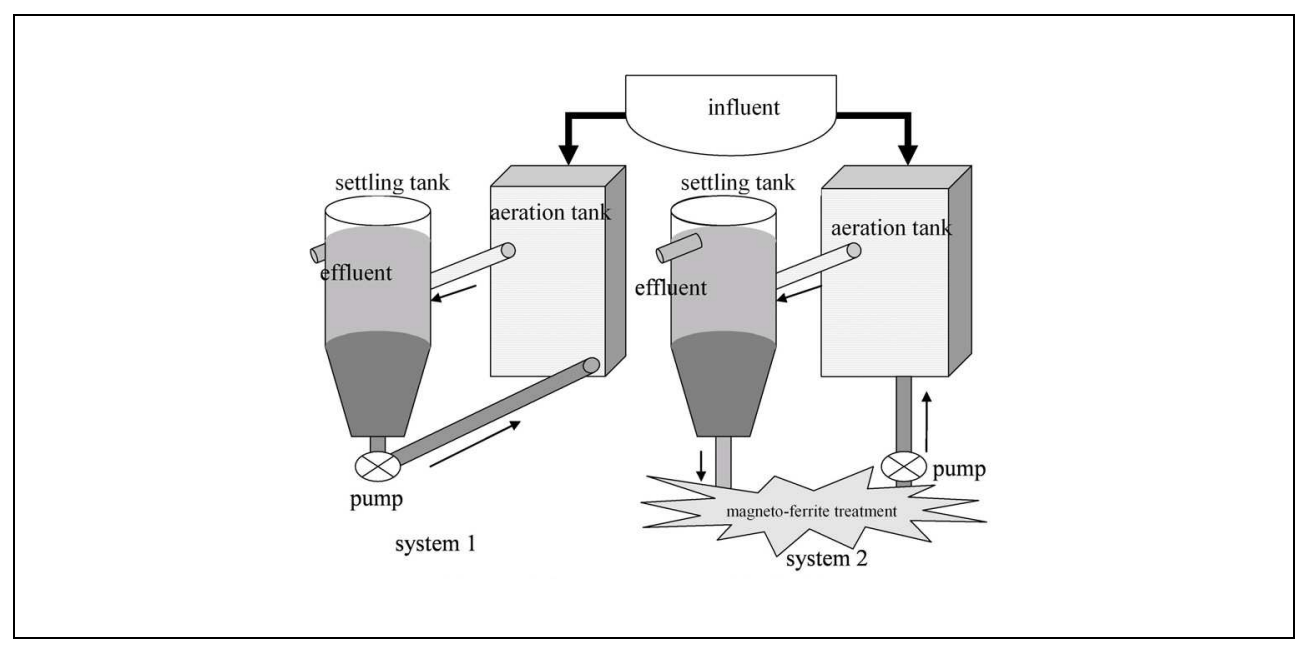

Fig. 5. Model diagram of two laboratory WWTPs 


\begin{tabular}{|l|c|c|}
\hline & CAS & EA \\
\hline BOD-Sludge Loading & 0.40 & 0.15 \\
\hline BOD-Volume Loading & 0.20 & 0.05 \\
\hline MLSS [mg/L] & 2000 & 3000 \\
\hline COD of Influent [mg/L] & 300 & 150 \\
\hline Amount of Influent [L/d] & 4.48 & 3.36 \\
\hline Aeration rate [L/min] & 3.00 & 3.00 \\
\hline
\end{tabular}

Table 1. The factors for the reduction of excess sludge

The COD of the influent was controlled at $300 \mathrm{mg} / \mathrm{L}$ for both systems for CAS method. It was $150 \mathrm{mg} / \mathrm{L}$ for EA method. The magneto-ferrite treatment device was run for $12 \mathrm{~h} / \mathrm{d}$. The ability of the return pump was fixed at $30 \mathrm{~mL} / \mathrm{min}$ of activated sludge. The return pump was operated for $1 \mathrm{~min}$ in every $30 \mathrm{~min}(1 \mathrm{~min} \times 2$ times (in $1 \mathrm{~h})$ ).

The experiments were continued for about 4 weeks for CAS method while it was run about 10 weeks for EA method. The MLSS of both two aeration tanks were measured periodically and controlled accordingly to the factors of the experiments. So, we drew up the excess sludge from the both aeration tanks and compared the amounts of the dried sludge. The results for CAS method will be described first. The amount of the excess sludge removed from the two systems can be seen in Fig. 6. It can be seen that for the first 2 weeks, the amount of excess sludge was about half comparing to the non treated sludge. However, later the difference in the amount of the excess sludge was getting closer to the nontreatment aeration tank's sludge. The BOD of the system 2 was not only from the waste

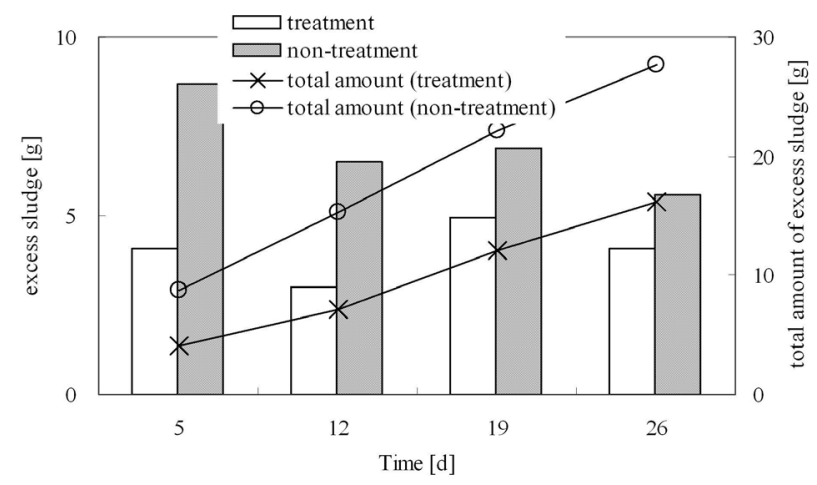

Fig. 6. Amount of discarded sludge during test tube treatment plant (CAS) 


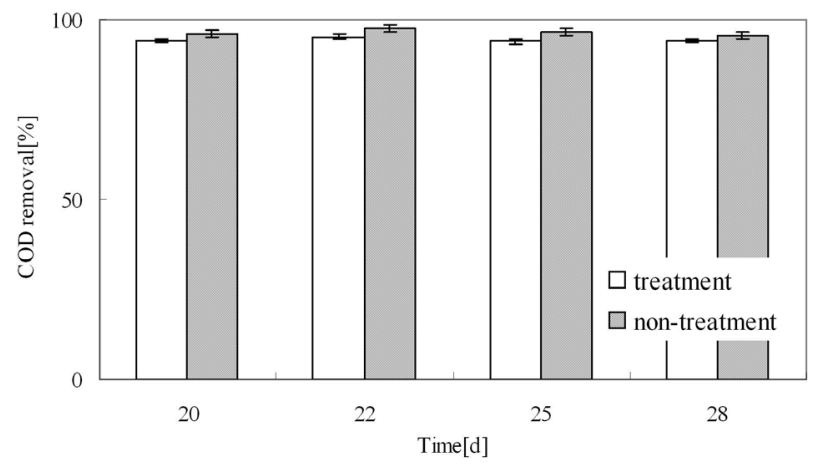

Fig. 7. COD removal efficiency during test tube treatment plant (CAS)

water, but it can be understood that the treated activated sludge was also contributed in the increasing of BOD of the relevant aeration tank. Thus the input BOD was greater than the non treated aeration tank (system 1) comparing to the system 2. This reason may influence the increase of excess sludge in system 2. So, a less amount of BOD is preferable to check the validity of the magneto-ferrite treatment on activated sludge in laboratory environment. The COD removal efficiency for CAS method was calculated and plotted in Fig. 7. It can be seen that the removal efficiency of COD of the activated sludge had been more than $90 \%$ in average. The error bar shows the standard deviation of the efficiency of COD removal of sludge for both the systems 1 and 2.

Again, the same WWTPs were run with EA process on which one was exposed to the magneto-ferrite treatment while the other one was run without any treatment. The values of the amount of the discarded sludge can be found in Fig. 8. It is clear that no excess sludge was found in system 2 which had been exposed to magneto-ferrite treatment for 10 weeks. As the whole conditions but the magneto-ferrite effect were same for the two aeration tanks, it is clear that the excess sludge was disrupted by magneto-ferrite treatment system. The values of initial stage of two systems were $2744 \mathrm{mg} / \mathrm{L}$ (system 1) and 3084 (system 2), respectively. The average of the MLSS for both aeration tanks were 3303 (system 1) and 2843 (system 2). The standard deviation values for both aeration tanks' MLSS were 351 for magneto-ferrite treatment and $546 \mathrm{mg} / \mathrm{L}$ for non-treatment system. These figures also proved the effectiveness of magneto-ferrite treatment on the excess sludge. The COD removal efficiency for EA method was calculated and plotted in Fig.9. It can be seen that for EA method, the removal efficiency of COD of the sludge were quite similar. The error bar shows the standard deviation of the efficiency of COD removal of sludge for both the systems 1 and 2. At the same time, the values of COD of the effluent for both systems as they were less than $20 \mathrm{mg} / \mathrm{L}$ in our observation period.

We checked the ferrite particles after 10 weeks after applying the magneto-ferrite treatment. The ferrite particles were collected, dried and observed by a photo microscope. The particles were found in the same size and shape of the initial stage of the experiment. 


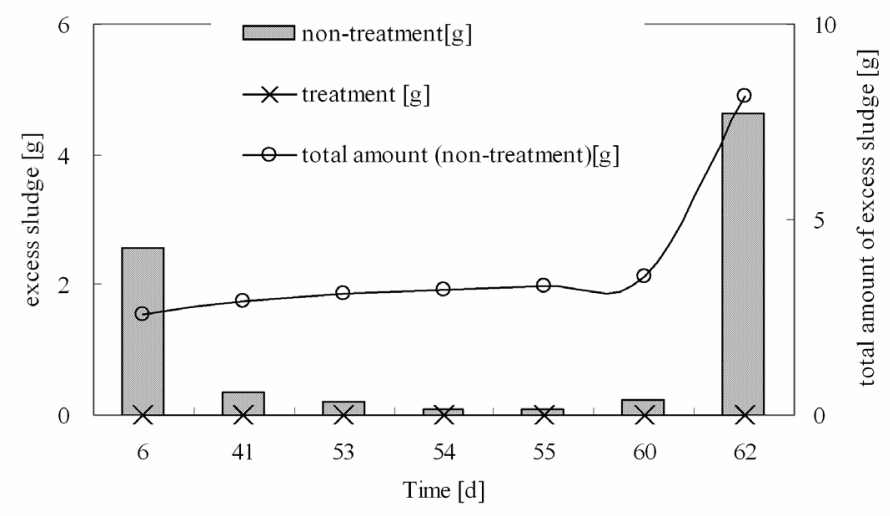

Fig. 8. Amount of discarded sludge during test tube treatment plant (EA)

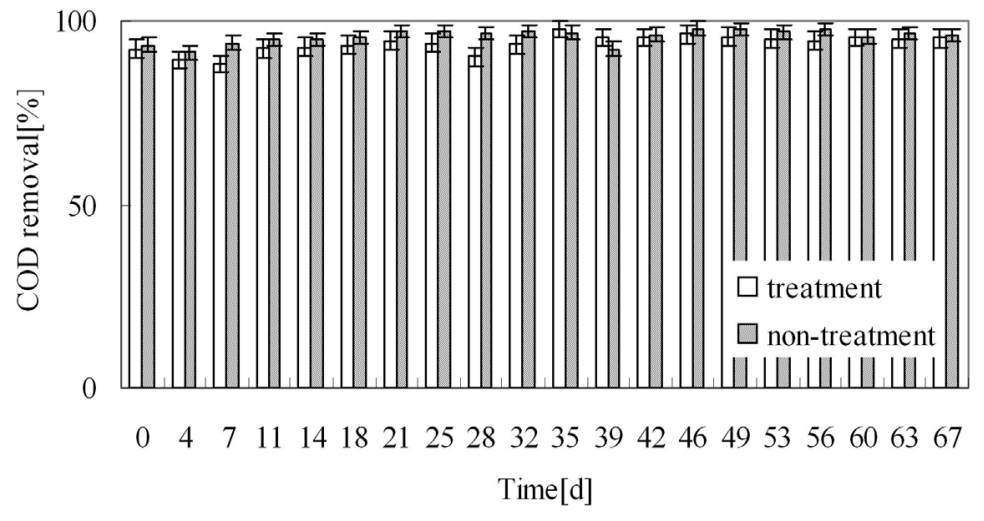

Fig. 9. COD removal efficiency during test tube treatment plant (EA)

Again, the magneto-ferrite treatment was applied for only $12 \mathrm{~h} / \mathrm{d}$, which showed a good result. These results proved that our new method is quite effective to reduce excess activated sludge in miniature WWTPs.

2.2.2 Rotary Plant (Kabir et al., 2010)

We succeded in sludge reduction with test tube plant in lab. scale. The general use of this method can only be possible if we can build up a treatment plant which can treat large amount of sludge at a time. However, it is not wise to make a larger test tube for large 
amount of sludge treatment. It can be understood that a larger plant should possess the following characteristics;

a. It can be applicable easily,

b. The setup cost is low and sound in economic,

c. It can be usable with the WWTPs easily

A rotary treatment plant can fulfill these demands. So, we proposed a rotary treatment plant which can be easily applicable with WWTPs (Fig.5). By the two miniature WWTPs, the validity of this method can be evaluated at the same room temperature and humid conditions. A brief explanation of the magneto-ferrite devices will be introduced here.

The rotary magneto-ferrite treatment plant can be seen in Fig.10. Two permanent magnets are set up on a rotor which is coupled with the shaft of a motor (M590-501K, Oriental Motor co.). The size and shape of the rotor is shown in Fig.11(a). The strength of a permanent magnet is $220 \mathrm{mT}$. An acryl plate is fixed above the rotor. This acryl plate is movable. A round shaped container is fixed on it. The magnetic flux in the container can be changed with the position of acryl plate. The size of the container is $17 \mathrm{~cm} \times 5 \mathrm{~cm}$ and it can contain $870 \mathrm{ml}$ of liquid. The material of the container is PVC. It is connected to the return sludge line of the miniature WWTP (system 2). A fixed amount of ferrite particles with activated sludge is kept in the container. A stirrer made of free plastic is placed in the container. Free plastic can be shaped in any size easily as it liquefies at $60^{\circ} \mathrm{C}$. The stirrer has a metal plate installed in it. There are two cuts in the corner side of the stirrer. When the stirrer moves the activated sludge can easily get under the stirrer. The top and front view of the stirrer can be seen in Fig.11(b).

The rotor circles when the shaft of the motor starts to move. At the same time, the stirrer and the ferrite particles of the container start to move with the magnets (Fig.10). The distance between the stirrer and ferrite particles is a very important factor in this method. This distance can be controlled by the magnetic flux. Though we could not measure this distance in this system, we chose a suitable magnetic flux working on the stirrer as well as ferrite particles by changing the position of the acryl plate in vertical direction. The stirrer with a metal plate in it is attracted to the bottom of the treatment container. The activated sludge is oppressed and stirred in the container. The collision is occurred with ferrite particles that cause the breakdown of the cell wall of microorganisms. Thus the sterilization is performed and the organic compounds are to be hydrolyzed in the solution. It will plug into the reduction of activated sludge.

To determine the parameters of the rotary magneto-ferrite system, several experiments were performed under several circumstances. For a certain amount of activated sludge, there should be a certain amount of ferrite particles. The speed of the motor that is connected to the speed of the rotor is an essential parameter. It can be understood that a faster rotor as well as moving magnets can make more collisions of ferrite particles and sludge. The treatment time is also important as it is related with running costs of the system.

So, we have performed three types of experiments to determine the parameters. They are as follows,

a. The density of magnetic flux,

b. The speed of the moving magnets (speed of motor) and

c. The amount of the ferrite particles.

Each experiment was followed by the written processes,

1. Initial amount of microbes were measured. Essential amount of activated sludge was taken to a beaker for it and it was kept at the room temperature. 
2. $300 \mathrm{ml}$ of activated sludge was taken to the container of rotary magneto-ferrite system. This activated sludge was cultured in laboratory's aeration tank.

3. Necessary amount of ferrite particles were added in the container.

4. The motor moved for a fixed time with a certain speed. Thus, the magneto-ferrite treatment was applied.

5. Viable cell was counted for treated activated sludge after each experiment. The living cell number was compared with that of the initial stage of activated sludge to justify the degree of sterilization. Sterilization linked to cell lysis.
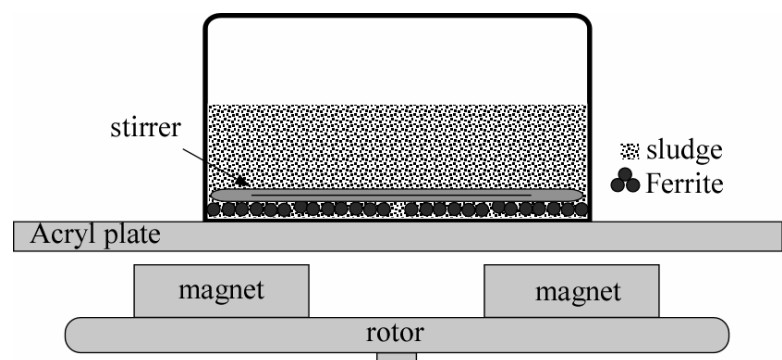

Fig. 10. Model diagram for rotary treatment plant

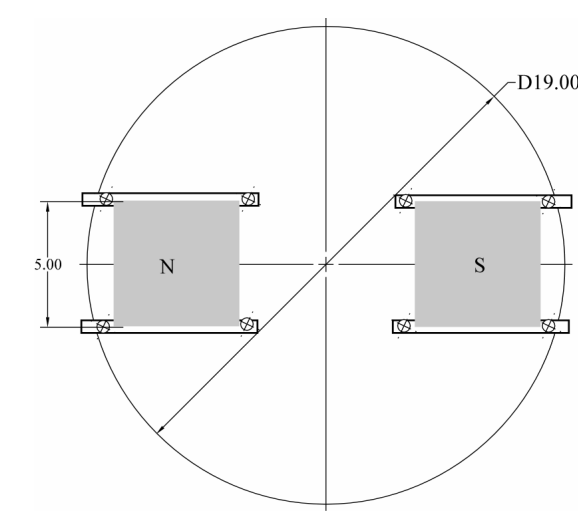

(a) rotor and magnets

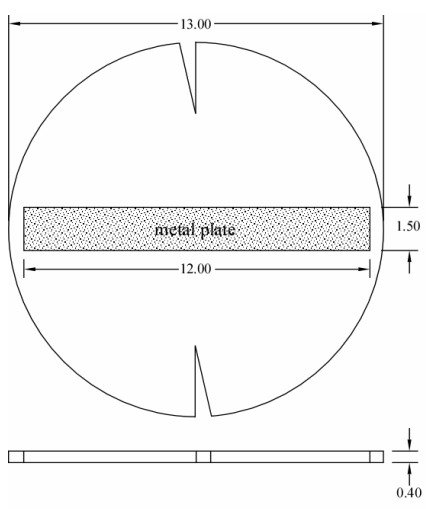

(b) stirrer

Fig. 11. Diagrams of the rotor and stirrer

The sterilization of the microbes was evaluated by calculating the VCC of the samples. 
First, we considered the movements of stirrer in the treatment container. If the magnets are too closer to the container, the stirrer as well as ferrite particles cannot move with the magnets for the stronger magnetic flux. The stirrer itself gets stick on the bottom of the container. So, we chose a suitable distance for magnets where the ferrite particles and stirrer can move smoothly. We could not measure the distance between the bottom of the container and the stirrer. From the Fig.10, it can be understood that this distance was very short. The magnetic flux in the container was about $30-50 \mathrm{mT}$ in average with the suitable position of acryl plate.

$100 \mathrm{~g}$ of ferrite particles were taken with activated sludge in the treatment container. It was sealed well so that the sludge could not overflow from the container. The motor of the rotary plant could rotate up to $1400 \mathrm{rpm}$. The speed of motor was 40rpm and treatment time was $1 \mathrm{~h}$. The viable cells of non-treated sludge and treated sludge were count before and after the experiments. Then VCC was calculated which had been 1-10\%. Other experiments were performed with $50 \mathrm{~g}$ of ferrite particles and speed of the motor. The conditions of the experiments and their results can be seen in Table 2. From, Table 2 it is clear that at least $1 \mathrm{~h}$ of treatment is necessary for this system. On the basis of VCC, it can be said that the sterilization was performed for 2 types of conditions (e.g. $100 \mathrm{~g}$ ferrite $+40 \mathrm{rpm}$ speed of motor \& 50g ferrite $+90 \mathrm{rpm}$ speed of motor). Both these conditions showed good sterilization performances but the stirrer had extra frictions with $100 \mathrm{~g}$ of ferrite particles which turned into the instability of the stirrer. So, we chose $50 \mathrm{~g}$ of ferrite particles for rotary treatment system.

Two miniature WWTPs were used to evaluate the effect of rotary treatment plant. The experiments were carried out in CAS method. The shape and the volume of the treatment container were $17 \mathrm{~cm} \times 5 \mathrm{~cm}$ and $870 \mathrm{ml}$ respectively. It can treat about $300 \mathrm{ml}$ of activated sludge at a time. The container was sealed tightly so that only the Roller pump could control the flow of the sludge in between settling tank and treatment container. The amount of influent and COD of influent were 3.36L/d and $400 \mathrm{mg} / \mathrm{L}$ respectively. The treatment time was $1 \mathrm{~h}$. Again, as this system can treat a large amount of sludge at a time comparing to test tube plant, the running time of this plant was only $4 \mathrm{~h} / \mathrm{d}$. In $6 \mathrm{~h}$, an hour of treatment was applied to the sludge. The Roller pump was used to send sludge from settling tank to treatment container.

The initial conditions for system 1 and system 2 were same. However, the initial values of MLSS of the two aeration tanks were little different. The experiment period was for about two weeks. MLSS of the two aeration tanks (system 1 and 2) were measured to evaluate the treatment effect. The measured data of MLSS and calculation data of COD removal efficiency are shown in Fig.12.

\begin{tabular}{|c|c|c|c|}
\hline Amount of ferrite $[\mathrm{g}]$ & Speed of motor $[\mathrm{rpm}]$ & Treatment time $[\mathrm{h}]$ & VCC [\%] \\
\hline 100 & 40 & 1 & $1-10$ \\
\hline 50 & 40 & 1 & 10 \\
\hline 50 & 90 & 1 & $1-10$ \\
\hline 50 & 90 & 0.5 & $10-100$ \\
\hline
\end{tabular}

Table 2. Determination of parameters for the rotary plant 
From the MLSS values, it can be seen that the activated sludge had been increasing with time in system 1 but it was well controlled in system 2 . The initial values of MLSS for system 1 and 2 were $1960 \mathrm{mg} / \mathrm{L}$ and $2482 \mathrm{mg} / \mathrm{L}$ respectively. After 2 weeks, it became 3954mg/L for system 1 and $3056 \mathrm{mg} / \mathrm{L}$ for system 2 . A simple calculation of activated sludge from the MLSS values showed that in system 2 (with magneto-ferrite treatment) only $3.8 \mathrm{~g}$ of sludge had increased while the non-treated aeration tank it had increased by $13.4 \mathrm{~g}$. So, it can be said that with this rotary plant, a total of $72 \%$ reduction had been possible in this experiment.

The calculation results of COD removal efficiency of the two WWTPs. There was not any significant difference between the removal efficiency of two miniature WWTPs due to the magneto-ferrite treatment. The magneto-ferrite treatment was applied for only $4 \mathrm{~h} / \mathrm{d}$, which showed a good result. These results proved that our new method is quite effective to reduce excess activated sludge in miniature WWTPs.

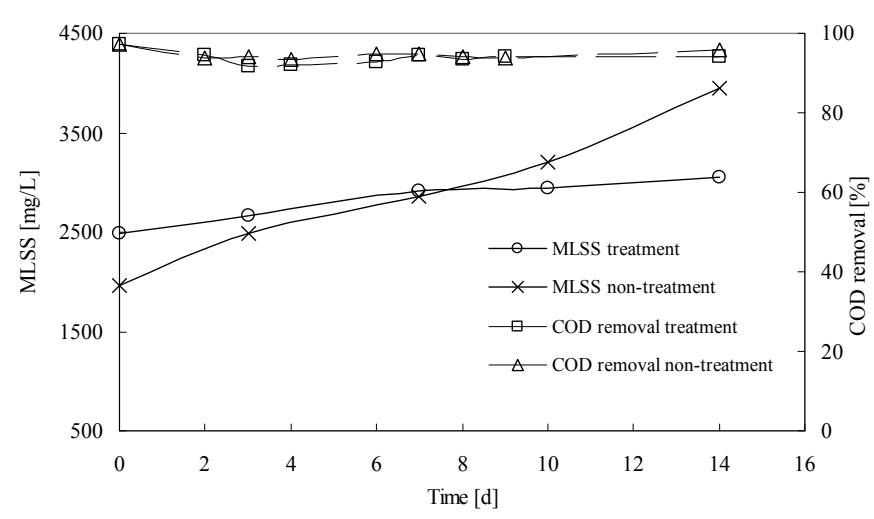

Fig. 12. Sludge reduction rotary treatment plant

2.2.3 Magneto-ferrite treatment with electromagnets (Kabir et al., 2012)

The motion of ferrite particles can be controlled by an electromagnet easily. Electromagnets can be operated with an AC supply. So, electromagnets may be helpful to use magnetoferrite treatment. If ferrite particles taken with activated sludge, can be steered up at a height and let it be down with a certain velocity then it can produce a lot of collisions with activated sludge to switch on to sterilization as well as reduction of sludge. The results have showed that electromagnets with AC supply can easily control the motion of ferrite particles. By controlling the movements of ferrite particles with activated sludge, sterilization and cell lysis of sludge have been achieved. It will pave the way of excess sludge reduction in WWTPs.

Two coils $(1.51 \mathrm{H}$ each) were set up in vertical direction with a certain gap in between them. These coils were connected with an AC voltage source (BP4610, NF). The coils were connected with 2 diodes (GSF05A40, VRRM=400V, IFAV=5A) which were installed in opposite direction to each other. The experimental setup model can be seen in Fig.13. The diodes were set up with the coil in a way that when the coils were connected with AC power supply, the electric current was provided alternative directions to the coils. 


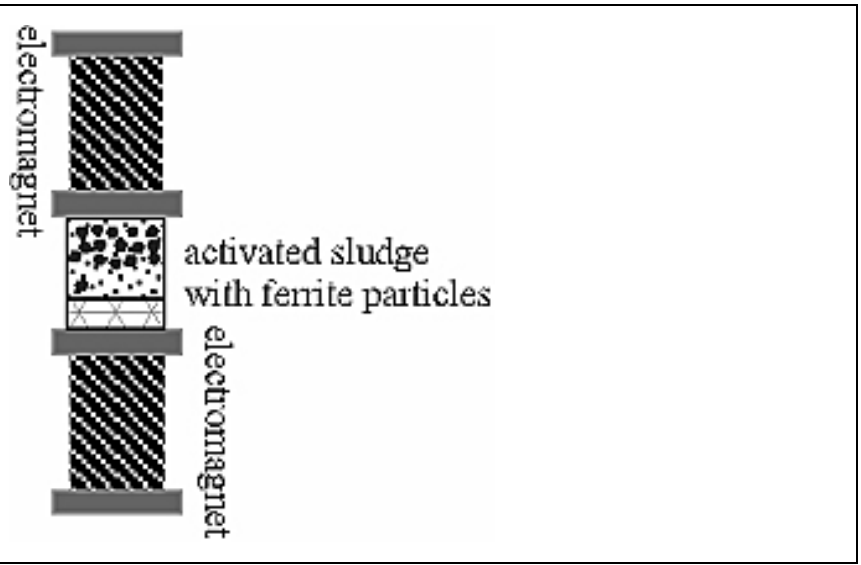

Fig. 13. Setup model diagram using electromagnets

Thus, the coils become electromagnets alternatively with the AC voltage source. A certain amount of ferrite particles and activated sludge were taken to the treatment container. Ferrite particles are magnetic substance and they move with the magnetic flux. While they moved in the container, collisions occured with the activated sludge. For a certain AC power supply with frequency, these collisions may break down the cell wall or cell membrane of bioorganisms of activated sludge. It may switch to sterilization and cell lysis of the activated sludge. If these treated sludge is taken to the aeration tank where they can be decomposed by the non-treated sludge, then the sludge reduction can be achieved.

At first, we measured the $I-V$ relationship with 2 types of wave. Sine wave and square wave were applied to the coils and we measured the electric current in it. Due to the limit of the voltage source, the voltage applied in the range of $0-120 \mathrm{Vp}-\mathrm{p}$. The electromagnetical charateristics of the coils were measured by a Gauss meter (GM04, HIRST MAGNETIC Instrument). Thus after learning the electrical properties and magnetical properties, we utilized them for several measurements regarding on sterilization and cell lysis of activated sludge.

The material of the treatment container was soft polyethelen and the shape was cylindrical $(\phi 41 \mathrm{~mm} \times 32 \mathrm{~mm})$. The capacity of the container was $40 \mathrm{ml}$. Considering the previous results of magneto-ferrite treatment, $9 \mathrm{~g}$ of ferrite particles were taken into the container with $20 \mathrm{ml}$ of activated sludge (Kabir et al., 2007, 2009). The treatment was applied for 1-3h.The ferrite particles and sludge were taken in this container and kept between the coils. A short description will be provided for the sterilization experiment. Activated sludge was taken from the aeration tank. An MLSS meter (SS-5F, KRK) was used to measure the MLSS of the sludge and the values were adjusted if needed. $20 \mathrm{ml}$ of sludge was taken in the container with $9 \mathrm{~g}$ of ferrite particles. Then sterilization process was investigated.

The $I-V$ relationship of the coils and voltage source was determined. The r.m.s. value was calculated for both voltage and current for the coils. The electrical characteristics were measured for the coils for square wave. The frequency was fixed at $1.0 \mathrm{~Hz}$. Fig.14 shows the measured data of current and magnetic flux produced by a coil. The current increased almost linearly in the coils with voltage. Magnetic flux also increased with current. As the maximum range of input voltage $(120 \mathrm{Vp}-\mathrm{p})$ the maximum value of current was found at $4.8 \mathrm{~A}$ in a coil and $594 \mathrm{mT}$ of magnetic flux was achieved. This magnetic flux was sufficient 
enough to move ups and downs of ferrite particles in the treatment container in our experiment.

The treatment was performed with the determined parameters. The treatment container with $20 \mathrm{ml}$ of sludge and $9 \mathrm{~g}$ of ferrite particles was set up on the lower coil. We made a room of $1-2 \mathrm{~mm}$ between the lower coil and treatment container. The frequency was chosen $1.0 \mathrm{~Hz}$ and the wave was $90 \mathrm{Vp}$-p of square wave. The seed activated sludge was taken from the Yabase Sewage Treatment Plant of Akita city, Japan. The seed activated sludge was cultured in miniature WWTPs run at Suzuki Lab. of Akita University. The MLSS was $3000-4000 \mathrm{mg} / 1$ of the sludge and their COD removal efficiency was about $94 \%$.

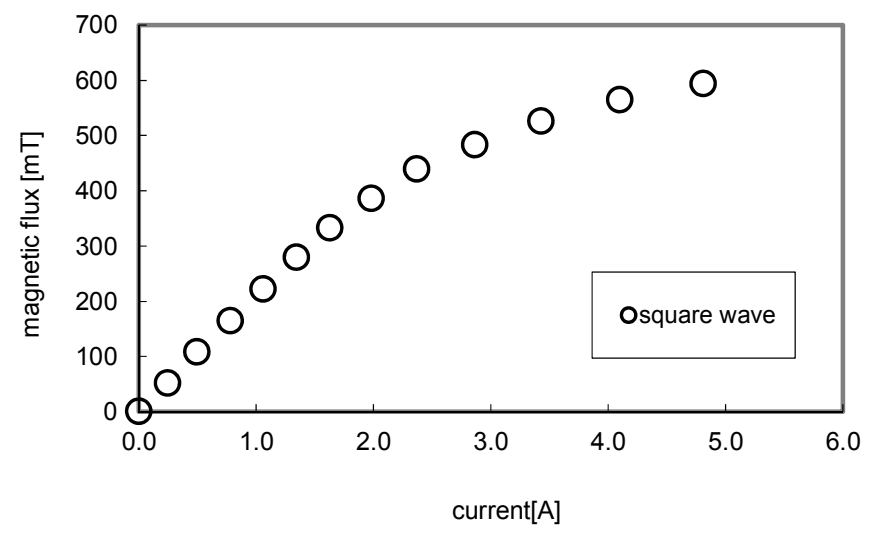

Fig. 14. B-I relationship of a coil

The sterilization of the activated sludge was investigated for 1-3h of treatment. When the treatment was carried on, $20 \mathrm{ml}$ of fresh activated sludge was kept at room temperature without any treatment. The viable cell was measured for each sample by Easycult T.T.C. The VCC was calculated after each experiment. The values of VCC for non-treated sludge was found $100 \%$ all the time during the experiments. The sterilization was confirmed with the treatment after $2-3 \mathrm{~h}$ of treatment to the sludge. The VCC decreased to $10 \%$ after $2-3 \mathrm{~h}$ of treatment to the activated sludge. The ferrite particles were moved ups and downs in the treatment container with magnetic flux. A larger magnetic flux can be helpful to produce more collisions of ferrite particles with the microorganism of activated sludge and thus sterilization is performed. Cell lysis can also be achieved at the same time of the sterilization with the electromagnets which can lead to the reduction of excess activated sludge.

\section{Conclusion}

Excess sludge is a problem which cannot be steered around in waste water treatment by biological analysis method. It is a growing demand to control the production of excess sludge for the sustainable WWT methods as well as the better society. We developed an innovative method with controlling ferrite particles' motion which resulted in the sterilization and cell lysis of sludge. 
It also points towards the new possibilities of this magneto-ferrite treatment. The method can be applied in the sterilization of the water of swimming pool, ballast tank not only in the reduction of activated sludge but it can be used of a cargo boat etc. As this process is a nonthermal sterilization method, many other uses can be expected. Again, this process can be used as a hydrolyzed method of activated sludge. Activated sludge is well known byproduct for its water retention ability. So, dewatering is very important process for the treatment of excess sludge. Our method can be helpful in it. One thing is to be noted that if we can be successful in reducing even $1 \%$ of total excess sludge produced in Japan every year, it can save about billions of Yen (Japanese currency; Yen) in a year. Thus, our methods have pointed out several possibilities in the view of both economical and environmental aspects.

\section{References}

Eckenfelder, W.W. \& Grau, P. (Eds.) (1998). Activated Sludge Process Design and Control: Theory and Practice (2nd ed.), Vol.1, Technomic Publishing Co., Lancaster

Ide, T. (1990). Water Treatment Engineering (2nd ed.), Gihodo Shuppan, ISBN 4-7655-3122-8, Tokyo [in Japanese]

Ito, T., Murayama, Y., Suzuki, M., Yoshimura, N., Iwano, K. \& Kudo, K. (1992). Evidence for sterilization of Saccharomyces Cerevisiae $\mathrm{K} 7$ by an external magnetic flux. Japanese Journal of Applied Physics, Vol.31, No.6A, pp. L 676-L678

Ghyoot, W. \& Verstraete, W. (1999). Reduced sludge production in a two-stage membraneassisted bioreactor. Water Resource, Vol.34, No.1, pp.205-215

Kabir, M. Suzuki, M. \& Yoshimura, N. (2007). Reduction of Excess Sludge by Ferrite Particles. Japanese Journal of Water Treament Biology, Vol.43, No.4, pp.189-197

Kabir, M. Suzuki, M. \& Yoshimura, N. (2009). Reduction of Excess Sludge by MagnetoFerrite Treatment: Observation on Lab Scale WWTPs. IEEJ Transactions on Electrical and Electronic Engineering, Vol.4, No.4, pp.584-586

Kabir, M. Suzuki, M. \& Yoshimura, N. (2010). Reduction of Excess Activated Sludge by Ferrite Particles: Methods for Practical Use. International Journal of the Society of Materials Engineering for Resources, Vol.17, No.2, pp.120-125

Kabir, M. Suzuki, M. \& Yoshimura, N. (2012). Excess Activated Sludge Reduction by Using Electromagnets and Ferrite Particles. IEEJ Transactions on Electrical and Electronic Engineering, Vol.7, No.2 (accepted)

Miyoshi, Y. (2006) Ideas and Techniques of Sewage and Wastewater Treatment, Ohmsha, ISBN 4274-02480-6, pp.55-169, Tokyo [in Japanese]

Murayama, Y., Itoh, T., Suzuki, M. \& Yoshimura, N. (1993). Effect of magnetic field and ferrite treatment on various organism. Transaction IEE of Japan, Vol.113-A, No.8, pp.594-595 [in Japanese]

Press release of Ministry of the Environment, Government of Japan (January 2010). Available from http://www.env.go.jp/recycle/waste/sangyo/sangyo_h19a.pdf [in Japanese]

Sano, A., Bando, Y., Yasuda, K., Nakamura, M., Senga, A. \& Kiyokawa, E. (2005). Enhancement in biodegradability of excess sludge by using centrifugal vibration mill. Journal of Chemical Engineering Japan, Vol.38, No.6, pp.446-449 
Sawada, Y., Nagashima, S., Uchida, T., Kawashima, N., Takeuchi, S., Akita, M. \& Nagaoka, H. (2005). Basic study on sludge concentration and dehydration with ultrasonic exposure. Japanese Journal of Applied Physics, Vol.44, No.6B, pp.4678-4681

Yasui, H. \& Shibata, M. (1994). An innovative approach to reduce excess sludge production in the activated sludge process. Water Science Technology, Vol.30, No.9, pp.11-20

Yoshida, T.(Publ.) (2000). Technologies for Minimization of Sludge and Reduction of Sludge Growth, NTS, Tokyo [in Japanese].

Yoshimura, N. \& Suzuki, H. (1991). Sterilizing effect on Yeast cells by ferrite powders. Transactions IEE of Japan, Vol.111-D, No.11, pp.988-989 [in Japanese]

Yoshimura, N., Suzuki, M. \& Sato, T. (1994). Microbic Handling by Means of Electricity and Magnetism. Journal of the Institute of Electrostatics Japan, Vol.18, No.1, pp.11-17 [in Japanese] 


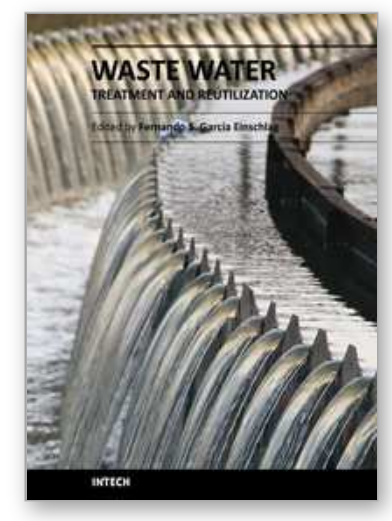

\author{
Waste Water - Treatment and Reutilization \\ Edited by Prof. Fernando Sebastiẽ $i n$ GarcÃa Einschlag
}

ISBN 978-953-307-249-4

Hard cover, 434 pages

Publisher InTech

Published online 01, April, 2011

Published in print edition April, 2011

The steady increase in industrialization, urbanization and enormous population growth are leading to production of huge quantities of wastewaters that may frequently cause environmental hazards. This makes waste water treatment and waste water reduction very important issues. The book offers a collection of studies and findings concerning waste water treatment, minimization and reuse.

\title{
How to reference
}

In order to correctly reference this scholarly work, feel free to copy and paste the following:

Mahmudul Kabir, Masafumi Suzuki and Noboru Yoshimura (2011). Excess Sludge Reduction in Waste Water Treatment Plants, Waste Water - Treatment and Reutilization, Prof. Fernando Sebastĩ̃ $i n$ GarcÃa Einschlag (Ed.), ISBN: 978-953-307-249-4, InTech, Available from: http://www.intechopen.com/books/waste-watertreatment-and-reutilization/excess-sludge-reduction-in-waste-water-treatment-plants

\section{INTECH}

open science | open minds

\author{
InTech Europe \\ University Campus STeP Ri \\ Slavka Krautzeka 83/A \\ 51000 Rijeka, Croatia \\ Phone: +385 (51) 770447 \\ Fax: +385 (51) 686166 \\ www.intechopen.com
}

\author{
InTech China \\ Unit 405, Office Block, Hotel Equatorial Shanghai \\ No.65, Yan An Road (West), Shanghai, 200040, China \\ 中国上海市延安西路65号上海国际贵都大饭店办公楼405单元 \\ Phone: +86-21-62489820 \\ Fax: +86-21-62489821
}


(C) 2011 The Author(s). Licensee IntechOpen. This chapter is distributed under the terms of the Creative Commons Attribution-NonCommercialShareAlike-3.0 License, which permits use, distribution and reproduction for non-commercial purposes, provided the original is properly cited and derivative works building on this content are distributed under the same license. 